\title{
Financiarización del desarrollo urbano en la Ciudad de México
}

Víctor Delgadillo

Universidad Autónoma de la Ciudad de México (UNAM), Colegio de Humanidades y

Ciencias Sociales, México.

Recibido: 21 de mayo de 2020. Aceptado: 12 de noviembre de 2020.

\begin{abstract}
Resumen
La financiarización es una forma de reproducción de capitales basada en inversiones en los mercados financieros globales. El mercado inmobiliario se ha convertido cada vez con mayor intensidad en un vehículo altamente lucrativo para la reproducción de capitales financieros y ha adquirido una escala colosal en varias ciudades del mundo. La financiarización del desarrollo urbano está contribuyendo a la profundización de la segregación socioespacial, la fragmentación urbana y la construcción de un despilfarro urbano, pues los inmuebles no se construyen en función de necesidades locales, sino como activos financieros en los mercados de capitales internacionales. Este artículo indaga en cómo ocurre la financiarización del desarrollo urbano en la Ciudad de México, a partir del análisis de una base de datos de 272 grandes desarrollos inmobiliarios, promovidos y realizados entre 2010 y 2020 , con sistemas de financiamiento articulados a inversiones internacionales. El artículo revisa las aportaciones latinoamericanas recientes sobre el tema de la financiarización del desarrollo urbano y la vivienda; y analiza los instrumentos financieros, las inmobiliarias involucradas y la política urbana local neoliberal, que permiten la captura de capitales foráneos en la edificación de colosales desarrollos inmobiliarios.
\end{abstract}

PALABRAS CLAVE: POLÍTICAS URBANAS. DESARROLLO URBANO INTENSIVO. FINANCIARIZACIÓN. CIUDAD DE MÉXICO.

\section{Financialization of urban development in Mexico City}

\begin{abstract}
Financialization is a form of capital reproduction based on investments in global financial markets. The real estate market has increasingly become a highly lucrative vehicle for the reproduction of financial capitals and has acquired a colossal scale in several cities of the world. The financialization of urban development is contributing to the deepening of socio-spatial segregation, urban fragmentation and the construction of an urban wastefulness, since buildings are not built according
\end{abstract}


to local needs, but as financial assets in international capital markets. This article investigates how the financialization of urban development occurs in Mexico City, based on the analysis of a database of 272 large real estate developments, promoted and carried out between 2010 and 2020, with financing systems articulated to international investments. The article reviews recent Latin American contributions on the topic of financialization of urban development and housing; and analyzes the financial instruments, the real estate agents involved and the neoliberal local urban policy, which allow the capture of foreign capital in the construction of colossal real estate developments.

KEY WORDS: URBAN POLICIES. INTENSIVE URBAN DEVELOPMENT. FINANCIALIZATION. MEXICO CITY.

PALAVRAS-CHAVE: POLÍTICAS URBANAS. DESENVOLVIMENTO URBANO INTENSIVO. FINANCEIRIZAÇÃO. CIDADE DO MÉXICO.

\section{Introducción}

En las últimas décadas, asistimos a la creciente financiarización del desarrollo urbano en muchas ciudades del mundo. Una forma de reproducción de capitales basada en las inversiones financieras en mercados bursátiles internacionales y no en la producción de mercancías materiales. La vivienda, el mercado inmobiliario y la industria de la construcción históricamente han requerido de financiamiento para su funcionamiento y han sido una fuente rentable para la inversión de los excedentes de capitales productivos diversos. Sin embargo, en años recientes, el mercado inmobiliario se ha convertido en un negocio muy lucrativo para capitales financieros internacionales provenientes de diversas fuentes y ha adquirido una escala colosal en varias ciudades. Hoy, los capitales financieros no están al servicio de la vivienda y de la industria de la construcción, sino que se sirven de ellos como vehículos para su reproducción altamente lucrativa. Así, la construcción de viviendas, oficinas, centros comerciales, infraestructuras, equipamientos y otros artefactos no responden a necesidades locales, sino a la reproducción de capitales internacionales. El suelo y los inmuebles (nuevos o existentes) se han convertido en títulos financieros móviles que se cotizan en el mercado financiero global.

El presente texto, basado en evidencias de una investigación en proceso, indaga cómo ocurre la financiarización del desarrollo urbano en la Ciudad de México, a partir del análisis de: los instrumentos financieros que permiten la captura de flujos de capitales foráneos para el desarrollo inmobiliario local; las empresas inmobiliarias articuladas a capitales trasnacionales; los grandes proyectos urbanos que se construyen en función de expectativas lucrativas internacionales; y la política urbana local que favorece estas inversiones inmobiliarias, a través de la flexibilización de la normatividad urbana y la construcción de obras públicas. Con respecto a las inmobiliarias, indagamos su origen, la procedencia de los capitales invertidos y su especialización inmobiliaria. Esta investigación se apoya en métodos cualitativos y cuantitativos. Construí una base de datos de 272 grandes desarrollos inmobiliarios, ${ }^{1}$ promovidos y realizados entre 2010 y 2020, con sistemas de financiamiento articulados a inversiones internacionales, a través de acciones colocadas en la Bolsa Mexicana de Valores, con información proveniente de dos revistas mexicanas

1 Excluí conjuntos de menos de 35 viviendas y la vivienda social que construye el gobierno local. 
especializadas: Real Estate Market \& Lifestyle y La Guía Inmobiliaria de México y Obras, desde el año 2010. ${ }^{2}$ A ello se suman recorridos de campo; visitas a show rooms; y consultas a sitios de internet.

Esta investigación ha sido motivada por las aportaciones de Carlos de Mattos y Raquel Rolnik. Leer sus investigaciones me planteó muchas preguntas. ¿Cómo ocurre la financiarización del desarrollo urbano en México? ¿Qué instrumentos jurídicos y financieros se utilizan para capturar flujos financieros internacionales en los mercados inmobiliarios locales? ¿Se financiariza sólo la vivienda o también la producción de edificios de oficinas, centros comerciales y otras infraestructuras? ¿Qué capitales aterrizan en esta ciudad? ¿Qué temporalidades e intensidades de financiarización se presentan en esta metrópolis? ¿La financiarización del mercado inmobiliario ha conducido a un desarrollo urbano expansivo y/o intensivo? En este texto se presentan respuestas parciales y preliminares a estas preguntas.

El artículo: (1) aborda los estudios sobre la financiarización del desarrollo urbano en Latinoamérica y discute algunas visiones europeas que continúan creyendo que los fenómenos que allí ocurren se trasladan a posteriori -con sus teorías y conceptos- al sur global; (2) caracteriza la financiarización del desarrollo inmobiliario en la capital mexicana, a partir del trabajo empírico y de antecedentes en las políticas públicas locales; (3) analiza las principales características de las inmobiliarias que actúan en la Ciudad de México, su ámbito territorial y especialización edilicia, y profundiza en las grandes inmobiliarias que actúan en el mercado bursátil; (4) analiza el papel proempresarialista del gobierno local que a toda costa promueve el negocio inmobiliario. El último apartado revisa brevemente algunos impactos del boom inmobiliario en una ciudad donde más del 50\% de sus residentes están excluidos del mercado formal del suelo y la vivienda. A manera de colofón, rescato las especificidades de la financiarización del desarrollo urbano y sus impactos sociales en la Ciudad de México.

\section{Financiarización y desarrollo urbano}

La financiarización es una forma de acumulación de capital que no se basa en la producción de mercancías materiales, sino en la compraventa de acciones, bonos y títulos en los mercados bursátiles y en los fondos de inversiones. Es decir, en la reproducción del capital en los mercados financieros. Industrias y empresas productoras de bienes materiales de muchos países invierten parte de sus ganancias en los mercados de valores. Igualmente, fondos sociales (de pensión, ahorros y vivienda), compañías de seguros e instituciones públicas de diversos países invierten parte de sus recursos, ahorros y presupuestos en inversiones bursátiles para incrementar su valor y evitar pérdidas por la inflación, devaluación o por mantener grandes cantidades de dinero en los bancos (De Mattos, 2016). Para Rolnik (2015) esas enormes inversiones financieras trasnacionales (integradas por capitales de diversos orígenes y países) constituyen una verdadera "muralla de dinero" que encuentra en las ciudades lucrativos mercados inmobiliarios en donde aterrizar. 
Lapavitsas (2016) sostiene que la financiarización, como concepto, tiene un origen en los estudios marxistas de la década de 1990 sobre la economía política; y como proceso se vincula a la globalización (del capitalismo neoliberal), que permitió la colosal expansión de las finanzas en escala planetaria.

Por su parte, Aalbers (2016 y 2017) dice que la financiarización es un concepto "vago y caótico", que permite problematizar conceptos existentes y constituye un gran esfuerzo por comprender de forma no lineal, multidimensional y multiescalar la complejidad de las sociedades y economías contemporáneas. En este sentido, Levy (2013) señala que, aunque hay varias definiciones de la financiarización, todas coinciden en la predominancia del capital financiero sobre otras formas de acumulación de capital. Lapavitsas (2016) agrega que la financiarización no tiene una forma homogénea válida para todo el mundo, pues la penetración de los mercados financieros está condicionada por las especificidades institucionales, políticas e históricas de cada país.

Para De Mattos (2016), la financiarización de la economía capitalista surge cuando la sobreacumulación de ganancias en la producción industrial ya no se puede reinvertir en ese mismo proceso productivo. Así que muchos excedentes de múltiples actividades económicas productivas se reinvierten directamente en los mercados bursátiles y/o en el segundo circuito de acumulación de capital: la urbanización. Esto no es nuevo. Se trata de una vieja característica del capitalismo, exacerbada por el neoliberalismo globalizado: el mercado inmobiliario era el segundo círculo de acumulación de capital (Lefebvre, 2013; Harvey, 2008).

La construcción de viviendas, oficinas o infraestructuras siempre ha requerido de financiamiento (público, privado o social) para su funcionamiento. Sin embargo, en años recientes, la vivienda y el mercado inmobiliario se han convertido en un negocio muy lucrativo para capitales financieros globales provenientes de diversas fuentes y han adquirido una escala colosal en varias ciudades (De Mattos, 2016; Rolnik, 2018; Shimbo y Rufino, 2019). Actualmente, los flujos financieros no están al servicio del financiamiento de la vivienda y del mercado inmobiliario. Al contrario, la vivienda y el mercado inmobiliario se han transformado en vehículos para la reproducción lucrativa de los capitales financieros internacionales. Se trata de un nuevo "imperio colonial" sin bandera y rostro, desterritorializado, abstracto, ficticio y lucrativo por naturaleza: las finanzas globales (Rolnik, 2015). La dimensión del negocio inmobiliario y financiero en el mundo es colosal:

》De Ribeiro y Diniz (2017) reconocen que los activos financieros globales pasaron de 12 a 209 billones de dólares entre 1980 y 2010, mientras que el Producto Interno Bruto (PIB) mundial creció de 11.8 a 55.9 billones de dólares en ese período. Así, los activos financieros se incrementaron casi cuatro veces más que el PIB mundial.

» Aalbers (2016) señala que actualmente hay más dinero en los activos financieros que en el Producto Interno Bruto global (ver Ruíz Tagle, 2020).

La base local y física de los negocios inmobiliarios es la propiedad privada de los inmuebles y del suelo, y los títulos que los transforman en papeles abstractos y en "activos" móviles, que representan la renta actual o futura en el mercado de capitales. El espacio construido se transforma en territorio para la renta, pues los bienes inmuebles tienen 
Financiarización del desarrollo urbano en la Ciudad...

un valor económico relativamente seguro que no se deprecia, por lo que constituye una garantía altamente valorada. Además, ofrece ventajas de escala, estandarización y un marco institucional que permite captar flujos de ingresos futuros (Fernández y Aalbers, 2016). Por estas cualidades, el mercado inmobiliario actualmente ofrece rentabilidades mayores que otras inversiones financieras y bancarias (De Mattos, 2016; Rolnik, 2015 y 2018). Para Daher (2013), la titulización de los bienes inmuebles no es una simple innovación de ingeniería financiera, sino una verdadera revolución financiera: los inmuebles que por su naturaleza son inmóviles se han convertido en altamente móviles a través de su titulización, mientras que los inversionistas no están atados a esos bienes raíces, pues en cualquier momento pueden vender sus acciones. La financiarización de los mercados inmobiliarios es promovida y garantizada por las políticas públicas de muchos gobiernos. Cada vez más países y ciudades han introducido mecanismos para la titulización de diversos ámbitos y segmentos del mercado inmobiliario, así como instrumentos institucionales ${ }^{3}$ que conectan el mundo inmobiliario con el mundo financiero y permiten la inversión inmobiliaria en distintas y distantes ciudades y países (Aalbers, 2016). Así, el sector inmobiliario sigue siendo local, pero el financiamiento es internacional.

La financiarización del mercado inmobiliario es diversa, no se reduce a un tipo de edificios, un solo ámbito territorial o un segmento del proceso inmobiliario. Los capitales financieros trasnacionales lo mismo invierten en la producción de vivienda, oficinas, centros comerciales, grandes infraestructuras, suelo o mercados de hipotecas. Sin embargo, algunos colegas opinan lo contrario. Abellán (2018:12) sostiene que la financiarización de la vivienda "se repite en todos los mercados inmobiliarios e hipotecarios a lo largo del planeta" y que "su implantación es inevitable". Mientras que Alexandri y Janoschka (2018:24) afirman que "la vivienda se ha vuelto decisiva para el capitalismo urbano financiarizado". Pero esto no es del todo así. Un análisis de los sistemas habitacionales de Bolivia, Perú o Cuba evidencian que la financiarización de la vivienda no ocurre en todas partes, ni es inevitable en el planeta. Aalbers (2016 y 2017) demuestra la diversidad de la financiarización de los sistemas habitacionales en Europa y Brasil, aunque haya trayectorias comunes: en distintos países se financiariza el mercado de hipotecas, la construcción nueva, los edificios existentes en alquiler o en propiedad privada, etcétera. En una misma ciudad las diferencias pueden ser notables.

Además, el "capitalismo urbano financiarizado" no se limita a la vivienda. En la Ciudad de México, como se verá enseguida, la financiarización de los mercados inmobiliarios actualmente está más vinculada a la construcción de centros comerciales, edificios de oficinas, hoteles y a una vivienda muy cara y no dirigida a un mercado hipotecario masivo. Lo mismo ocurre en Madrid, donde la burbuja inmobiliaria financiarizada dejó 3.4 millones de viviendas vacías: el actual megaproyecto Madrid Nuevo Norte evidencia que los negocios inmobiliarios trasnacionales se dirigen a los equipamientos culturales, centros comerciales y torres de viviendas muy caras. Así, puede ser que la vivienda sea "decisiva para el capitalismo urbano financiarizado", pero sólo en ciertos períodos, países y ciudades. Entonces, siguiendo la tesis del capitalismo neoliberal realmente existente (Brenner y Theodore, 2017) y los estudios de Lapavitsas (2016),

3 Los Trust de Inversiones en Bienes Raíces nacieron en EE. UU. hacia 1960. En varios países se han reproducido estas figuras que gozan de incentivos fiscales para capturar capitales financieros internacionales en mercados inmobiliarios locales. Por ejemplo: Certificados de Recebíveis Imobiliários en Brasil, o Fideicomisos de Inversión en Bienes Raíces en México. 
entendemos que hay una pluralidad muy amplia de formas de financiarización de los (sub)mercados inmobiliarios, con distinta intensidad, territorialidad y temporalidad. El área metropolitana de la Ciudad de México, y sus ciclos de expansión horizontal y vertical, es un buen ejemplo de ello.

Aquí, conviene recordar que los desarrollos urbanos expansivos e intensivos no son aspectos diferentes o sucesivos, sino parte de la misma lógica del desarrollo urbano y de la acumulación de capitales. En algunos momentos se acentúan tendencias de desarrollo urbano expansivo, planificado o no, a través de la construcción masiva de viviendas o de la formación de asentamientos irregulares; $y$ en otros períodos prevalece la verticalización urbana selectiva, a través de procesos de destrucción creativa. Ambos procesos, simultáneos, sucesivos y yuxtapuestos, se guían por lógicas del mercado y de la maximización de las rentas urbanas. Rolnik (2018) ha dado cuenta de que la financiarización y la mercantilización del desarrollo urbano y de la vivienda, después de producir millones de viviendas en periferias urbanas distantes de distintos países ${ }^{4}$-con millones de ellas vacantes-, actualmente se dirigen a las áreas urbanas existentes, preferentemente centrales, a través de una nueva frontera de mercado, incluyendo la vivienda en alquiler y la supuesta "economía compartida” de, por ejemplo, el sistema AirBnB.

\section{¿Una trayectoria del norte al sur global?}

Aalbers (ver Ruíz Tagle, 2020) afirma que la financiarización de la vivienda que ocurría quince años atrás en el "norte global", 5 actualmente se reproduce en el sur global. Sin embargo, en esta misma entrevista él reconoce que Brasil, desde 1997, había adoptado figuras jurídicas que facilitaban la captura de capitales globales para los negocios inmobiliarios y que muchos países europeos apenas en el siglo XXI comenzaron a financiarizar sus sistemas habitacionales. Otras colegas latinoamericanas (Shimbo y Rufino, 2020) sostienen que la investigación sobre la financiarización del desarrollo urbano se inició en Europa y EE. UU., donde las ciudades ya no eran solamente financiadas y producidas por actores urbanos históricos. Tales afirmaciones desconocen las aportaciones latinoamericanas que ya habían advertido el creciente papel de las finanzas internacionales en la producción local de viviendas y del desarrollo urbano: Duhau (2008) hablaba de "los nuevos productores del espacio urbano", Pradilla denunciaba la fusión del capital financiero e inmobiliario con el poder político, y Ortiz (2007) daba cuenta del monopolio de las constructoras en México que producían cientos de miles de viviendas y cotizaban en mercados bursátiles. En efecto, los estudios sobre los grandes proyectos urbanos, la gentrificación y la ciudad neoliberal, desde principios del siglo XXI, ya habían identificado la creciente presencia de capitales financieros en los procesos de reestructuración urbana, en la vivienda y en el medio ambiente construido, sin profundizar expresamente sobre la financiarización inmobiliaria.

Así, la financiarización no es un concepto parteaguas en los estudios urbanos, sino una herramienta conceptual y analítica que plantea una continuidad con los estudios sobre el urbanismo neoliberal, con énfasis en la presencia decisiva de los capitales financieros internacionales en la reconfiguración de las ciudades.

4 En Chile surgió esta forma de producción de "vivienda social” que se reprodujo en México, Brasil y Sudáfrica.

5 Se refiere a EE. UU. y el Reino Unido y, en menor medida, a Grecia, España y Portugal. 


\section{Perspectivas latinoamericanas}

La creciente presencia de las finanzas internacionales en el sector inmobiliario, facilitada y promovida por gobiernos de distinta orientación política, ha impulsado un conjunto de investigaciones sobre la financiariación del desarrollo urbano en distintas ciudades latinoamericanas, notablemente en Brasil. Así, a los pioneros trabajos de De Mattos (2007) y Rolnik, se pueden sumar un número temático de la revista Cadernos Metrópole (De Queiroz y Diniz, 2017), el libro de Shimbo y Rufino (2019) y un seminario internacional realizado en Buenos Aires, en 2019, coordinado por Rodrigo Fernández e Ivana Socoloff (SOMO, 2019). Entre estas recientes aportaciones hay trabajos que se centran en las reflexiones teóricas y otros que hurgan en especificidades materiales del mercado inmobiliario financiarizado. De Queiroz y Diniz (2017) anclan su visión sobre la producción del espacio dominada por capitales financieros en la teoría de los ciclos sistémicos de acumulación del capital. Klinik y Barcellos (2019) revisan el origen y evolución del concepto con el objetivo de entender cómo la lógica financiera ha permeado en la vivienda, el desarrollo urbano y las formas de gestión y planeación urbana. Otras investigaciones se centran en aspectos específicos: las grandes inmobiliarias, el acaparamiento de suelo urbano como reserva de valor, diversos instrumentos urbanísticos, el mercado hipotecario, la vivienda, la infraestructura o las alianzas público-privadas (Shimbo y Rufino, 2019). Varios colegas dan cuenta de que la crisis mundial de 2008 implicó el desplazamiento de inversiones inmobiliarias internacionales a mercados inmobiliarios latinoamericanos. Daher (2013), por su parte, enfatiza la concentración metropolitana de las inversiones inmobiliarias de los fondos de inversión, pero advierte que a nivel intrametropolitano estas inversiones son selectivas.

Una constante transversal es el papel decisivo del Estado, a través de políticas públicas y de la asociación público-privada. En este sentido, Aalbers (2016) señala que la financiarización no tiene nada que ver con el supuesto neoliberal de "menos Estado y más mercado". Palomero (2019) añadiría que el "libre" mercado es un mito: el Estado garantiza las altas rentas a los mercados financieros.

\section{Financiarización inmobiliaria en la Ciudad de México}

La consolidación de la doctrina y sistema económico neoliberal reconfiguró la economía mexicana. En este contexto, un primer ciclo de financiarización del desarrollo urbano se centró en la producción de más de 10 millones de viviendas de "interés social”, de pésima calidad constructiva y habitable, realizada entre 2000 y 2012 en periferias urbanas distantes. Ortiz (2008) advirtió que de 1.200 empresas constructoras que participaban en ese negocio, 9 monopolizaban el $25 \%$ de la producción habitacional y 6 participaban en la Bolsa Mexicana de Valores. Para apoyar estos procesos, en diciembre de 2005, se emitió la Ley del Mercado de Valores ${ }^{6}$ que incluye a los desarrollos inmobiliarios como un elemento muy activo del mercado bursátil. Rolnik (2015) demuestra que inversionistas ingleses (Equity International) fondearon la inmobiliaria HOMEX y la utilizaron para hacer negocios lucrativos con la vivienda social en México. Gracias a esos fondos, HOMEX pasó de construir de 5 mil a 60 mil viviendas al año. Frente al ocaso de este negocio, Equity International emigró a Brasil para lucrar con un mercado similar de viviendas sociales en periferias urbanas distantes. 
Otros antecedentes de la financiarización de la vivienda en México son destacados por Winter (2019): la banca está en un 75\% en manos del capital extranjero, igual que el $45 \%$ de las pensiones y más del 50\% de los seguros; mientras que el Instituto Nacional del Fondo de Vivienda para los Trabajadores (INFONAVIT), institución que desde su fundación en 1972 capta el $5 \%$ de los ingresos de los trabajadores, estableció alianzas con entidades financieras para impulsar nuevas formas de financiamiento a la vivienda: en 2004 estableció una línea de crédito en cofinanciamiento (CONFINAVIT) y Certificados de Vivienda (CEDEVIS) en la Bolsa Mexicana de Valores (bono respaldado por hipotecas). Salinas (2019:114-115) registra que entre 2000 y 2015 el INFONAVIT otorgó 6.7 millones de créditos a su población derechohabiente para la adquisición de una vivienda en el "libre" mercado, mientras que, entre 2007 y 2012, se otorgaron casi 3 millones de créditos. Por su parte, el Censo de Población y Vivienda de 2010 reveló que en México había 5 millones de viviendas vacías.

Posteriormente, el gobierno federal desarrolló diversos instrumentos financieros para favorecer el mercado inmobiliario:

» En 2009 se crearon los Certificados de Capital de Desarrollo, de manera simultánea a diversos cambios en el sistema de Administración de Fondos para el Retiro, que permiten canalizar pensiones de los trabajadores a la inversión en infraestructuras, comunicaciones, minería y desarrollo inmobiliario.

» En 2011 se crearon los Certificados Bursátiles Fiduciarios Inmobiliarios y los Fideicomisos de Inversión en Bienes Raíces (FIBRAS), para promover la compra y construcción de inmuebles de venta o arrendamiento, con facilidades fiscales y administrativas para integrar inversiones diversas (pequeñas y grandes, locales y extranjeras) de inversionistas individuales o en grupo. Los FIBRAS obtienen sus rentas fijas de la venta o alquiler de los inmuebles incluidos en los portafolios de inversiones inmobiliarias, y las rentas variables dependen de la apreciación de los certificados bursátiles en la Bolsa Mexicana de Valores. La Ley de Impuesto sobre la Renta vigente, en sus Artículos $\mathrm{N}^{\circ} 187$ y 188 , establece la condonación de diversos impuestos a los fideicomisos y empresas dedicados a la construcción y adquisición de inmuebles.

» En 2015 se crearon los Certificados de Proyectos de Inversión para financiar proyectos. Este instrumento permite que un administrador (y no un Comité) decida sobre las inversiones.

En marzo de 2018, las doce FIBRAS registradas ante la Bolsa Mexicana de Valores tenían 1.640 propiedades, un área bruta rentable de 21 millones de metros cuadrados y activos por 491.945 millones de pesos, que casi duplicaban los de la cadena de supermercados Wal Mart México (Vázquez, 2018a). Vale agregar que una inmobiliaria no necesita constituirse en FIBRA para emitir Certificados Bursátiles Fiduciarios Inmobiliarios y capturar inversiones de los mercados financieros.

La revista Obras (2018) reconocía que el mercado inmobiliario de México era uno de los más apreciados por los inversionistas globales, porque los retornos de inversión (del 10 al 40\%) estaban por encima del 8\% que otros instrumentos ofrecían: si antes faltaba financiamiento, "hoy se podría naufragar en el dinero que busca dónde pegar tabiques" (Obras $\left.N^{\circ} 542,2018: 1\right)$. En este mismo sentido, Vázquez (2018b) reconocía 
Financiarización del desarrollo urbano en la Ciudad...

Víctor DELGADILLO

que la inversión en inmuebles, en este caso en vivienda, protege los ahorros e inversiones de la gente contra la inflación y las fluctuaciones del precio del dólar, pues entre 2012 y 2018 los precios de la vivienda aumentaron más que los precios al consumidor y la inflación, y se equipararon al alza del dólar.

\section{Inmobiliarias y mercado bursátil en la Ciudad de México}

De los 272 megaproyectos inmobiliarios registrados: 120 son torres de departamentos, 66 centros comerciales, 40 torres de oficinas, 8 torres de corporativos, ${ }^{7} 28$ megaproyectos de uso mixto, 5 proyectos viales, 3 hoteles, un teatro y un acuario. Miguel Hidalgo es la Alcaldía que más megaproyectos aloja (67), fundamentalmente se trata de la urbanización de áreas ex fabriles. Le siguen Cuauhtémoc (46), Álvaro Obregón (45), Benito Juárez (24), Azcapotzalco (19), Coyoacán (13), Tlalpan (10), Gustavo A. Madero (10), Cuajimalpa (9), Iztacalco (9), Iztapalapa (7), Xochimilco (4), Venustiano Carranza (2) y Magdalena Contreras (1). Tláhuac y Milpa Alta no presentan megaproyectos. Esta lógica territorial de localización de los megaproyectos refleja la histórica segregación socioespacial de la Ciudad de México (Figura 1). ${ }^{8}$

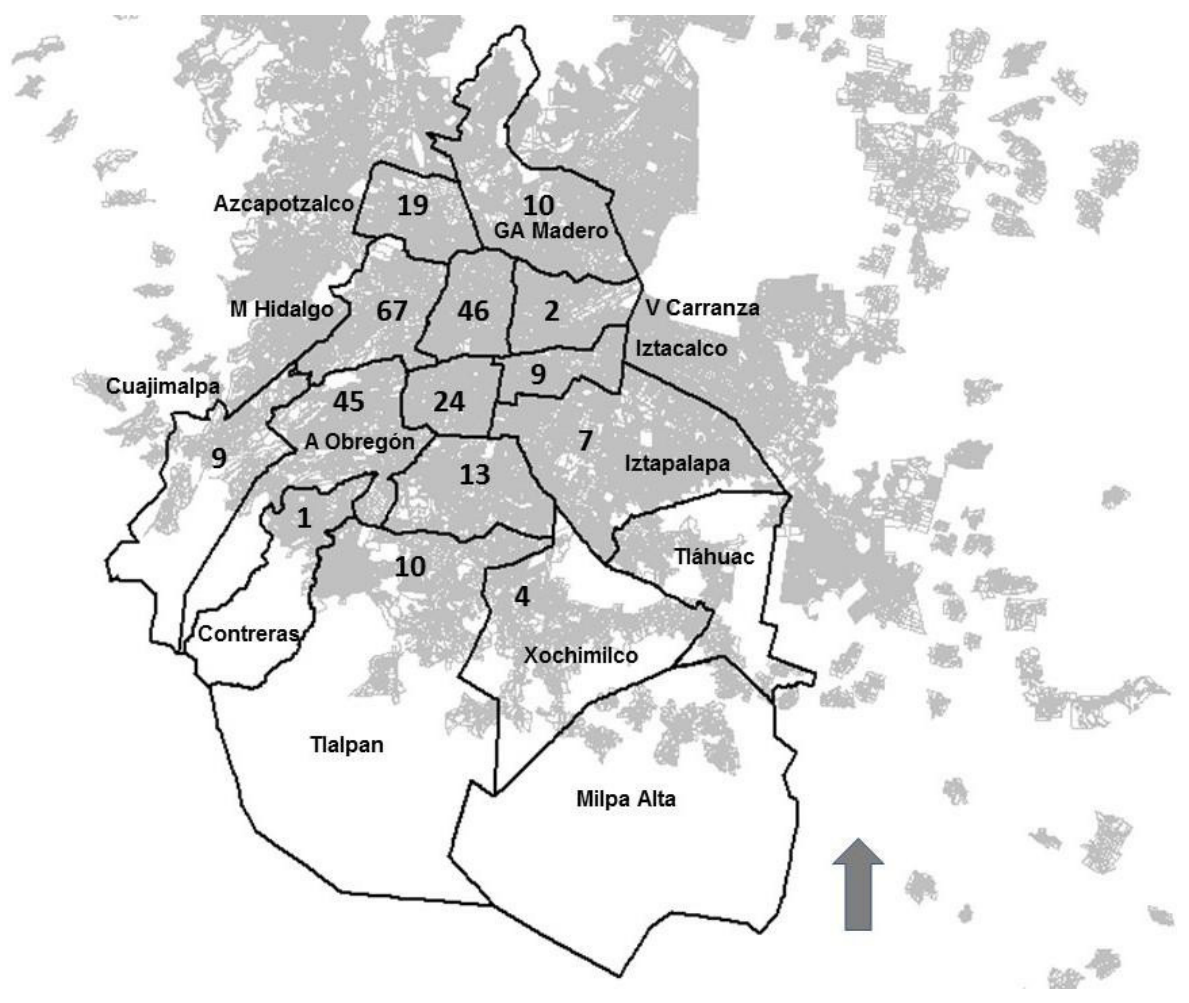

Figura 1. Concentración de proyectos inmobiliarios por alcaldía. Fuente: elaboración propia.

7 Los edificios de oficinas rentan espacios atomizados. Los edificios de corporativos alojan oficinas destinadas al uso de una sola empresa o corporativo.

8 El norte y el sur de la Ciudad de México históricamente han sido ocupados por sectores populares y equipamientos y usos indeseables (prisiones, fábricas, rastro). En cambio, los sectores de mayores ingresos ocupan los mejores terrenos del sur poniente. En Iztapalapa vive el $20 \%$ de los capitalinos y en Gustavo A. Madero el $13 \%$. Así, en dos Alcaldías que se caracterizan por la precariedad y la falta de servicios habita la tercera parte de la población. 
Financiarización del desarrollo urbano en la Ciudad...

Víctor DELGADILLO

De los 272 megaproyectos identifiqué a las 22 inmobiliarias con el mayor número de proyectos, con el objeto de profundizar en el conocimiento de sus portafolios inmobiliarios, territorios de actuación, inversiones en bolsa de valores y captura de inversiones foráneas.

Antecedentes de negocios. Tres empresas que se dedicaban a otras actividades económicas, incursionaron recientemente en el negocio inmobiliario para diversificar sus negocios. DANHOS y GICSA provienen de la industria textil. Be Grand se dedicaba a la industria automotriz y la infraestructura. City Towers inició construyendo vivienda de interés social en conjuntos de dimensiones relativamente pequeñas. Grupo Sordo Madaleno realizaba únicamente proyectos arquitectónicos.

Cantidad de proyectos. Las inmobiliarias que más proyectos tienen son COPRI (35), CARSO (27), GICSA (20), Be Grand (19), Fibra UNO (18), Mexico Retail Properties (17), DANHOS (14), ABILIA (12) y City Towers (9) que juntas suman el 62.8\% de todos los desarrollos inmobiliarios. COPRI y CARSO, por sí mismas, constituyen el $22.8 \%$ del total.

Ámbito territorial y especialización inmobiliaria. La mayoría de las inmobiliarias tiene presencia en varias ciudades del país y algunas en América Latina, EE. UU. y España. Las empresas que se dedican fundamentalmente a desarrollar torres de vivienda residencial y vivienda residencial plus ${ }^{9}$ concentran sus actividades en selectos territorios: City Towers en Xoco (Figura 2), LAR en Nuevo Polanco, COPRI en Santa Fe, y MIRA y GAF entre Santa Fe y Polanco. Be Grand tiene una mayor dispersión territorial en selectos territorios valorizados y accesibles a través de vialidades primarias. En todos los casos se incluyen diversas amenidades como spa, gimnasio, salón de juegos, albercas, bares y otros servicios. Se trata de tener la "ciudad" dentro del edificio, para que la gente no salga a la calle.

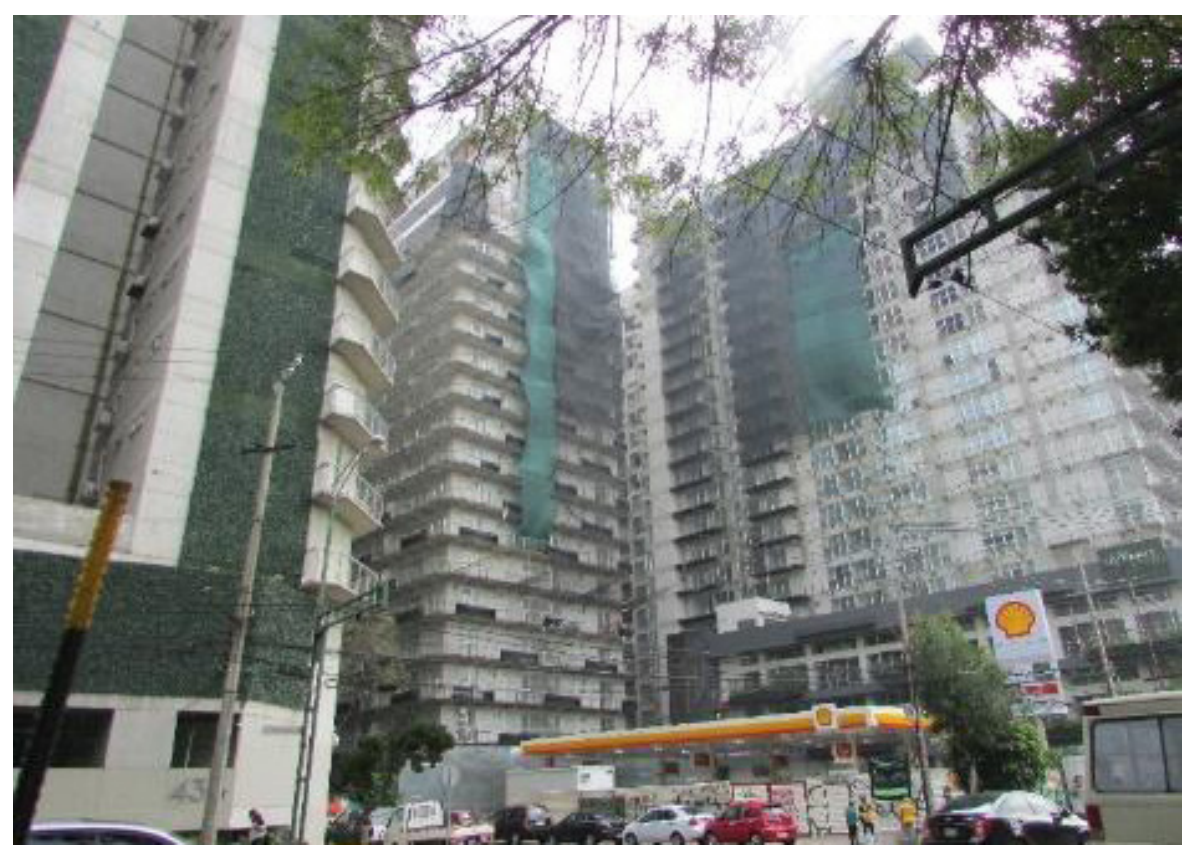

Figura 2. Torres de departamentos City Towers (Xoco). Foto: fotografía propia.

9 La Ley de Vivienda de la Ciudad de México define a la vivienda en función de su costo: vivienda de interés social hasta 25.305 dólares (febrero 2020), vivienda de interés popular hasta 42.175 dólares (ambos tipos prácticamente no se construyen por los costos del suelo). La vivienda media vale hasta 100.000 dólares, la vivienda residencial hasta 216.0000 dólares y la vivienda residencial plus más que la última. 
Financiarización del desarrollo urbano en la Ciudad...

Víctor DELGADILLO

Cinco inmobiliarias se especializan en la construcción de megaproyectos de vivienda media en edificios con alturas de hasta 22 pisos (Buen Hogar, Cubo 3 Mil, ENKSA, MARHNOS y Quiero Casa). Algunos de sus masivos proyectos abarcan una manzana completa. Estas inmobiliarias se concentran en Azcapotzalco e Iztacalco, aunque la última inmobiliaria tiene proyectos dispersos en Coyoacán.

Las empresas especializadas en centros comerciales tienen una relativa dispersión territorial en barrios de clase media y alta. Sin embargo, algunas inmobiliarias empezaron a construir Malls en áreas accesibles de barrios populares: DANHOS, DLG e IQ.

Las empresas más grandes, que cuentan con una mayor diversidad de desarrollos inmobiliarios, presentan también mayor dispersión territorial a pesar de que algunas de ellas se concentran en selectos enclaves urbanos: CARSO en Nuevo Polanco, ABILIA en Polanco, Fibra UNO y Pulso Inmobiliario en Paseo de la Reforma (Figuras 3 y 4).
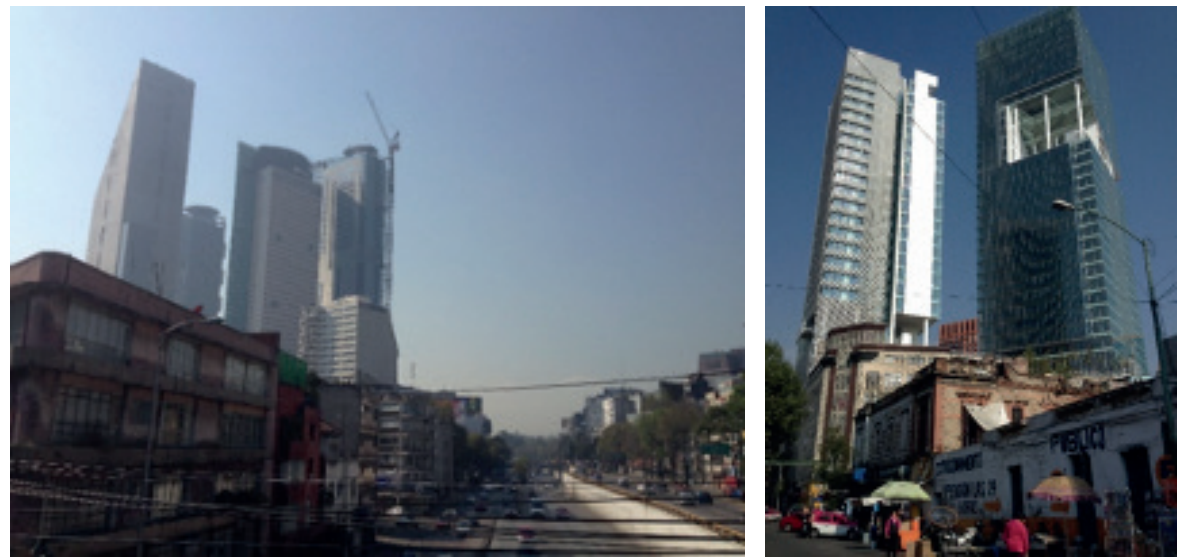

Figuras 3 y 4. Torres Reforma, Mayor y Chapultepec Uno; y Torres Cuarzo. Fotos: fotografía propia.

Construir para vender y alquilar. La mayoría de las inmobiliarias que producen vivienda residencial, media y popular lo hacen para la venta, aunque ABILIA y Pulso Inmobiliario también producen vivienda para alquiler. En cambio, el alquiler es el negocio de quienes producen y operan centros comerciales y edificios de oficinas. En los centros comerciales un ingreso constante proviene del servicio de estacionamiento. Algunas constructoras de vivienda para estratos socioeconómicos medios y altos, en sus estrategias de venta abiertamente sugieren a sus potenciales clientes que compren y alquilen sus propiedades a través de la plataforma AirBnB, es decir, que compren departamentos como negocio.

Participación en el mercado bursátil. Ciento setenta y nueve megaproyectos (65.8\% de la base de datos) están articulados a flujos de capitales globales, a través de la Bolsa Mexicana de Valores.

Hay tres inmobiliarias estadounidenses: Mexico Retail Properties, MIRA y Thor Urbana, que suman 24 megaproyectos (8.82\% del total). A su vez, dos grandes fondos de inversión financian sus actividades inmobiliarias. Por un lado, Black Creek Group, con sede en Denver (EE. UU.) y presente en México desde 1996, dispone de fondos propios, fondos de pensiones, fundaciones, instituciones financieras y pequeños inversionistas. 
En 2014 fundó en México “Gran Ciudad” definida como una inmobiliaria que está cambiando en las ciudades mexicanas la idea de la vivienda en alquiler. Este grupo fondea las inversiones de MIRA y Mexico Retail Properties. Por otro, Ivanhoé Cambridge, subsidiaria del fondo de pensiones canadiense CDPQ, fondea el Certificado de Proyecto de Inversión de MIRA ${ }^{10}$ con 4.180 millones de pesos mexicanos y, desde 2019, también a "Gran Ciudad" con un fondo de 6.000 millones de pesos mexicanos, a través de Certificados de Capital de Desarrollo, para que esta empresa constituyera un portafolio de inversiones inmobiliarias.

Cuatro inmobiliarias con 57 megaproyectos (20.09\%) no presentan información de sus actividades bursátiles en sus páginas de internet. Sin embargo, hay varias evidencias de que sus desarrollos inmobiliarios están vinculados al mercado de valores:

»ABILIA es una inmobiliaria subsidiaria de Tresalia Capital, un fondo de capital privado y de riesgo que compra acciones y ofrece financiamiento. La propietaria de ambas instituciones es la misma persona.

" COPRI es parte del Club Cumbres de Santa Fe, que ofrece a compradores de inmuebles y a inversionistas en general inversiones con tasas anuales del 8.14\% al 27.67\%, en distintos desarrollos inmobiliarios.

" Grupo LAR, inmobiliaria española, no reporta acciones bursátiles en México, pero si en España, donde constituye una Sociedad de Inversión (SOCIMI) que goza de una fiscalidad especial desde 2012, similar a las FIBRAS en México.

" Grupo Sordo Madaleno no presenta información sobre su actividad bursátil en su página de internet, pero si en los medios de comunicación. En 2018 anunció la emisión de Certificados de Proyectos de Inversión por 7.500 millones de pesos.

Cinco inmobiliarias con 98 megaproyectos (36.02\% del total) presentan información bursátil completa: dos se encuentran constituidas expresamente como FIBRAS y las otras tres inmobiliarias no, pero igualmente reportan de forma trimestral las actividades que realizan en la Bolsa Mexicana de Valores y la valorización de sus acciones (Cuadro 1).

» Fibra UNO cotiza en la Bolsa Mexicana de Valores desde 2011 y reconoce que el 30\% de sus ganancias proviene de la renta de sus inmuebles y el 70\% de la apreciación de su capital, a través de adquisiciones y desarrollos.

» Fibra DANHOS emite certificados bursátiles desde 2013 y la inmobiliaria CARSO desde 2012.

》 Be Grand emitió en 2018 sus primeros Certificados de Capital de Desarrollo y Certificados Bursátiles Fiduciarios Inmobiliarios.

» GICSA ha emitido Certificados Bursátiles Fiduciarios Inmobiliarios durante cuatro años consecutivos. 
Financiarización del desarrollo urbano en la Ciudad...

Víctor DELGADILLO

Cuadro 1. Actividad bursátil de cinco inmobiliarias en la Ciudad de México. Fuente: elaboración propia.

\begin{tabular}{|c|c|c|c|c|}
\hline Inmobiliaria & $\begin{array}{l}\text { Emisión Certificado Bursátil } \\
\text { Fiduciario Inmobiliario }\end{array}$ & $\begin{array}{l}\text { Millones de } \\
\text { pesos }\end{array}$ & Plazo & $\begin{array}{c}\text { Ganancia } \\
2018-2019\end{array}$ \\
\hline \multirow{4}{*}{ Fibra DANHOS } & DANHOS 2013 & - & - & \multirow{4}{*}{$15.3 \%$} \\
\hline & DANHOS 2016 & 3,000 & 2026 & \\
\hline & DANHOS 20162 & 1,000 & 2019 & \\
\hline & DANHOS 2017 & 2,500 & 2027 & \\
\hline \multirow{7}{*}{ FIBRA UNO } & 2011 & 3,615 & & \multirow{7}{*}{$11.9 \%$} \\
\hline & 2012 & 8,876 & - & \\
\hline & 2013 & 23,000 & 2023 & \\
\hline & 2014 & 32,810 & 2044 & \\
\hline & 2016 & 4,500 & 2027 & \\
\hline & 2017 & 3,800 & 2027 & \\
\hline & 2018 & 5,400 & 2023 & \\
\hline \multirow{2}{*}{ Be Grand } & GRANDCK 2018* & 4,000 & 2028 & \multirow{2}{*}{$117 \%$} \\
\hline & BEGRAND 18 & 1,500 & 2021 & \\
\hline \multirow{4}{*}{ CARSO } & INCARSO 2012 & 5,000 & 2017 & \multirow{4}{*}{$14.4 \%$} \\
\hline & INCARSO 2013 & 3,000 & 2018 & \\
\hline & INCARSO 2015 & 4,000 & 2025 & \\
\hline & INCARSO 2017 & 3,971 & 2027 & \\
\hline \multirow{4}{*}{ GICSA } & GICSA 2015 (a) & 2,500 & 2018 & \multirow{4}{*}{$31.8 \%$} \\
\hline & GICSA 2015 (b) & 500 & 2022 & \\
\hline & GICSA 2016 & 2,999 & 2023 & \\
\hline & GICSA 2017 & 1,000 & 2022 & \\
\hline
\end{tabular}

* Certificados de Capital de Desarrollo

El resto de las inmobiliarias (34.19\% de proyectos) no incluye información sobre inversiones en la Bolsa Mexicana de Valores y parecen estar desconectadas de la economía financiarizada.

\section{Un gobierno proempresarialista}

De Mattos (ver Delgadillo, 2016b) señala que los gobiernos consideran a las inversiones inmobiliarias como muy positivas en sus territorios, pues, aunque respondan a lógicas de reproducción de capitales foráneos y los precios de los edificios y viviendas construidas estén fuera del alcance de las poblaciones locales, la industria de la construcción genera empleos, los edificios nuevos dan la imagen de una ciudad que progresa y el área de impuesto predial se incrementa.

En los últimos 20 años, los gobiernos locales de la Ciudad de México han desplegado un conjunto de continuas políticas de desarrollo urbano intensivo, con distintos énfasis e instrumentos urbanísticos (Delgadillo, 2016a). El gobierno de López Obrador (20002006) promovió el repoblamiento y densificación de las cuatro Delegaciones (alcaldías) centrales. Marcelo Ebrard (2006-2012) contra reformó la Ley de Desarrollo Urbano de la capital mexicana para favorecer la lucrativa densificación edilicia de selectos 
Financiarización del desarrollo urbano en la Ciudad...

Víctor DELGADILLO

territorios urbanos. Mientras que el gobierno de Miguel Ángel Mancera (2012-2018), el más pro empresarialista, fue omiso frente a las violaciones a las normas urbanas para favorecer los negocios inmobiliarios.

Frente al creciente malestar ciudadano contra la multiplicación de mega desarrollos inmobiliarios, Mancera decía que él no frenaría el desarrollo inmobiliario y que es un grave error poner obstáculos a la inversión en las ciudades (Cruz y Gómez, 9 de mayo de 2017). Mancera no sólo apoyaba las inversiones inmobiliarias, sino que las promovía a través de agencias de gestión urbana (Agencia de Promoción, Inversión y Desarrollo para la Ciudad de México, creada en 2007, y Agencia de Gestión Urbana, creada en 2013), así como de las Zonas de Desarrollo Económico y Social (ZODES). Dos ZODES fueron suspendidas por oposición vecinal, y dos avanzaron sustancialmente: Ciudad de la Salud, en torno al complejo privado de la empresa Médica Sur, y Ciudad Gubernati$v a$ en la colonia Doctores. Varios Centros de Transferencia Modal de distintos modos de transporte se concesionaron por 40 años a inversionistas privados para realizar proyectos inmobiliarios. Algunos de estos megaproyectos han sido cancelados por la nueva jefa de gobierno (2018- 2022), tal vez más por la necesidad de diferenciarse del gobierno anterior, que por atender a las protestas ciudadanas.

Estamos hablando de un sexenio en el que hubo un enorme boom inmobiliario. La Asociación de Desarrolladores Inmobiliarios decía que, entre 2012 y 2017, ellos construyeron 156 edificios con 20.4 millones de metros cuadrados y una inversión de 15 mil millones de dólares (Cruz, 18 de abril de 2018). Para diciembre de 2018, Cruz (3 de diciembre de 2018) consignaba que entre 2012 y 2018 se habrían construido y autorizado 292 desarrollos inmobiliarios de alto impacto con 19.4 millones de metros cuadrados.

Corrupción inmobiliaria y malestar ciudadano. Gran parte de los proyectos e inmobiliarias consignadas en este estudio han sido relacionadas con violaciones a normas urbanas diversas: usos del suelo, niveles de construcción permitidos y trámites varios. En muchos casos, ciudadanos y vecinos no sólo han desarrollado protestas contra estos megaproyectos, sino que han denunciado las obras ante tribunales locales. Sin embargo, no siempre se trata de corrupción. La Ley de Desarrollo Urbano de la Ciudad de México, a través de diversas contrarreformas, contiene muchas modalidades e instrumentos para modificar los usos del suelo y las intensidades constructivos al servicio del lucro inmobiliario: Polígonos de Actuación, Áreas de Gestión Estratégica, Sistema de Actuación por Cooperación, Sistema de Transferencia de Potencialidad de Desarrollo, entre otros.

Sin embargo, en otros casos, hay evidencias claras de violación al número de niveles permitidos, obras sin autorización, etcétera. En nuestro registro periodístico de denuncias ciudadanas ante distintas instituciones públicas, aparecen en las decenas de notas: suspensiones temporales realizadas por el Instituto de Verificación Administrativa (INVEA); recomendaciones y denuncias penales de la Procuraduría Ambiental y del Ordenamiento Territorial (PAOT) y de la Procuraduría Federal del Consumidor; juicios y resoluciones favorables a las empresas o a los ciudadanos del Tribunal de lo Contencioso Administrativo; recomendaciones de la Comisión de Derechos Humanos del Distrito Federal; quejas y denuncias de los alcaldes, Asamblea Legislativa y de la Contraloría del Gobierno de la Ciudad de México, entre otros. Así, frente a estas flagrantes violaciones diversas, destacaba la postura del Jefe de Gobierno Miguel Mancera, quien 
pedía no suspender las obras, sino dar tiempo para que las constructoras atendieran las observaciones y regularizaran sus edificaciones (Cruz, 13 de enero de 2015).

Desde 2016 comenzaron a emitirse algunos dictámenes jurídicos del Tribunal de lo Contencioso Administrativo y del INVEA, que demandaban la demolición de pisos construidos de manera ilegal. Sin embargo, en muy pocos casos esto ocurrió. El ex titular de la PAOT aseguraba en 2019 que los pisos ilegales excedentes se demolieron en diez inmuebles y que restaban por demoler "439 pisos irregulares" (González y Quintero, 1 de febrero de 2019).

Obras viales en favor de inmobiliarias. Otra forma en que los gobiernos locales apoyan la realización de grandes proyectos inmobiliarios es a través de obras viales que facilitan la accesibilidad de los nuevos desarrollos inmobiliarios. Cito tres ejemplos:

» En 2012, se hizo un paso a desnivel sobre la avenida Ejército Nacional para facilitar el acceso de las inversiones de CARSO, Polárea, ABILIA, Miyana y otras inmobiliarias muy activas en Nuevo Polanco.

» En 2018 se hicieron adecuaciones en dos secciones del Anillo Periférico Sur, con nuevas entradas y salidas al carril de alta velocidad, para facilitar la accesibilidad del Centro Comercial Artz Pedregal y Be Grand Alto Pedregal.

» El deprimido de Mixcoac, inaugurado en 2017, facilitó la accesibilidad a varios megaproyectos como Mitikah y Torre Manacar. En este caso, la empresa Pulso Inmobiliario reconocía que esta obra incrementó la plusvalía en la zona.

COPRI es una empresa que encontró la forma de realizar negocios inmobiliarios en Santa Fe, a cambio de construir vialidades públicas y de peaje, que serían necesarias y que gobierno "no puede costear". A cambio de construir el Puente de los Poetas, el gobierno local le cedió terrenos públicos y cambió la normatividad del suelo de conservación ecológico, para que COPRI construyera edificios de departamentos exclusivos.

\section{Consecuencias del boom inmobiliario}

Junto con el malestar ciudadano derivado de diversas causas, ${ }^{11}$ la principal consecuencia del boom inmobiliario ha sido el incremento de los precios del suelo y de la vivienda en la Ciudad de México, con el consecuente éxodo de la población para quien la ciudad se ha encarecido. Esto ha sido reconocido por las mismas autoridades que señalan que, a pesar del boom en la construcción de viviendas, unas cien mil personas al año (274 al día) abandonaban la ciudad por los costos de las mismas (Romero, 23 de julio de 2015). Para la Asociación de Profesionales Inmobiliarios de la Ciudad de México, la capital del país encontró "su vocación" en la vivienda residencial por el encarecimiento del suelo (La Redacción, 17 de julio de 2017). Por su parte, el INEGI reconocía que 737.742 personas salieron de la Ciudad de México, entre 2005 y 2010, y que un 52\% se fue a radicar al Estado de México (INEGI, 2019).

11 Ruido, sombra, obstrucción de vías públicas, daños "colaterales", derrumbes, hundimientos en calles, incremento de tráfico, disminución de agua. 


\section{Colofón}

La financiarización del desarrollo urbano es muy diversa. En la Ciudad de México y su zona metropolitana es posible observar dos ciclos de urbanización financiarizada con distintos instrumentos, tipos de inmuebles y territorios. Un primer ciclo, consistió en la producción de millones de viviendas sociales de pésima calidad en periferias urbanas distantes, facilitada por el otorgamiento de créditos hipotecarios a derechohabientes por parte de organismos públicos de vivienda. Aquí, un pequeño monopolio de constructoras multiplicó sus ganancias y captó capitales financieros, a través de la emisión de acciones en la Bolsa Mexicana de Valores. Un segundo ciclo, en parte yuxtapuesto al anterior, es el actual proceso de densificación de selectas áreas urbanas centrales con la construcción de torres de oficinas, centros comerciales, desarrollos inmobiliarios mixtos y vivienda cara. Aquí, la captura de capitales financieros se da a través de las FIBRAS y la emisión de Certificados Bursátiles Fiduciarios Inmobiliarios.

Estos instrumentos financieros, que han permitido capturar flujos de capitales globales para ser invertidos en el mercado inmobiliario sin tortuosos procesos notariales, dinamizaron colosalmente la industria inmobiliaria y de la construcción en la capital mexicana. Algunas empresas que se dedicaban a otras actividades económicas incursionaron al negocio inmobiliario.

Los distintos gobiernos de "izquierda" de la Ciudad de México han facilitado, de muy diversas formas, la realización de los desarrollos inmobiliarios: a través de la flexibilización de la normatividad urbana que libera el suelo para la captura de enormes rentas urbanas; el otorgamiento de exenciones fiscales y facilidades administrativas; no sancionando las violaciones a la normatividad urbana; y realizando obras viales que facilitan la accesibilidad de los nuevos megaproyectos urbanos. Además, el gobierno ha construido parques públicos al lado de estos megaproyectos.

Un efecto perverso del desarrollo urbano financiarizado es que las viviendas y los espacios construidos, por sus altos precios, están fuera del alcance de la mayoría de la población local; a la vez que se generan incrementos de los precios del suelo y de la propia vivienda. Esto se transforma en presiones (in)directas para los habitantes de la ciudad: los desalojos forzosos e indirectos son una constante en estos barrios. Otro efecto perverso consiste en que esos megaproyectos no serán utilizados, o completamente habitados, porque fundamentalmente son "activos" de inversiones trasnacionales. En contraste, hay déficit de espacios que requiere la población para vivir y hay espacios urbanos habitados que se han encarecido y amenazan con ser conquistados por las inversiones inmobiliarias. Lo lamentable es que no sólo no existen políticas para usar los espacios construidos deshabitados, sino que se continúan construyendo espacios urbanos que no serán habitados.

Las autoridades locales electas en 2018 han tenido la necesidad de revisar cuidadosamente varios proyectos en curso y autorizados y, frente a descaradas violaciones al marco jurídico, han clausurado y suspendido temporalmente algunas obras. Sin embargo, muchos proyectos inconclusos siguen su marcha y otros proyectos autorizados en la administración anterior comienzan a ser construidos. Está por verse de qué manera se continuará desarrollando el mercado inmobiliario en la Ciudad 
Financiarización del desarrollo urbano en la Ciudad...

Víctor DeLGADILlo

de México: si nos encontramos frente a un fin de ciclo o a una nueva ola de negocios inmobiliarios que respetarán el marco jurídico.

Sin embargo, más allá de la evolución y fuerza de los mercados inmobiliarios financiarizados, el mayor desafío para el gobierno local es desplegar políticas públicas que garanticen la permanencia de la población residente, a través de opciones habitacionales asequibles. 


\section{Q Bibliografía}

» Aalbers, M. (2016). Financialization of Housing, a political economy approach. Londres y Nueva York: Routledge.

»Aalbers, M. (2017). The Variegated Financialization of Housing. International Journal on Urban and Regional Research, 41, 542-554.

» Abellán, J. (2018). Capitalismo, vivienda y financiarización: una aproximación a la obra de Manuel Aalbers. En L. Salinas y A. Pardo (Coords.), Vivienda y migración, aportes desde la geografía crítica (pp. 73-105). México: UNAM.

»Alexandri, G. y Janoschka, M. (2018). ¿Quién pierde y quién gana de una crisis de vivienda? Aprendizajes de España y Grecia para una comprensión matizada de la desposesión. En L. Salinas y A. Pardo (Coords.), Vivienda y migración, aportes desde la geografía crítica (pp. 23-69). México: UNAM.

» Brenner, N. y Theodore, N. (2017). Las ciudades y las geografías del capitalismo realmente existente. En Á. Buitrago (Editor), Neil Brenner, teoría urbana crítica y políticas de escala (pp. 113-159). Barcelona: Icaria.

"Cruz, A. (13 de enero de 2015). Frena Mancera paro innecesario de obras; no significa impunidad. La Jornada, 27.

»Cruz, A. (18 de abril de 2018). Inmobiliarias erigieron 20.5 millones de $\mathrm{M}^{2}$ de edificios este sexenio. La Jornada, 28.

» Cruz, A. (3 de diciembre de 2018). Invadieron la ciudad 19.4 millones de $\mathrm{m}^{2}$ de concreto y acero en esta administración, La Jornada, 26.

" Cruz, A. y Gómez, L. (9 de mayo de 2017). Mancera: creció 27\% la industria de la construcción por alianza con la IP. La Jornada, 28.

»Daher, A. (2013). Territorios de la financiarización urbana y de las crisis inmobiliarias, Revista de Geografía Norte Grande, 56, 7-30.

»De Mattos, C. (2007). Globalización, negocios inmobiliarios y transformación urbana. Nueva Sociedad, 212, 82-96.

»De Mattos, C. (2016). Financiarización, valorización inmobiliaria del capital y mercantlización de la metamorfosis urbana. Sociologías, 18(42), 24-52.

»Delgadillo, V. (2016a). Ciudad de México: 15 años de desarrollo urbano intensivo. La gentrificación percibida. Revista INVI, 31(88), 101-129.

» Delgadillo, V. (2016b). Financiarización y mercantilización del desarrollo urbano en escala planetaria. Entrevista a Carlos A. de Mattos. Andamios, Revista de Investigación Social, 13(32), 213-243.

»Duhau, E. (2008). Los nuevos productores del espacio habitable. Ciudades, 79, 21-27.

» Fernández, R. y Aalbers, M. (2016). Financialization and housing: Between globalization and Varieties of Capitalism. Competition \& Change, 20(2), 71-88.

» González, R. y Quintero, J. (1 de febrero de 2019). Ignoró el gobierno anterior las solicitudes de la PAOT: Cancino. La Jornada, 28. 
Financiarización del desarrollo urbano en la Ciudad...

» Harvey, D. (2008). Espacios del Capital: Hacia una geografía crítica. Madrid: Akal.

» INEGI - Instituto Nacional de Estadística, Geografía e Informática (2019). Movimientos migratorios, emigración interna. Recuperado de: http://cuentame. inegi.org.mx/monografias/informacion/df/poblacion/m_migratorios. aspx?tema $=$ me\&e $=09$.

» Klinik, J. y Barcellos, M. (2017). Financeirização: conceitos, experiências e a relevância para o campo do planejamento urbano brasileiro. Cadernos Metrópole, 19(39), 379-406.

»La Redacción (17 de julio de 2017). Hasta 25 mil dólares llega a costar un $\mathrm{M}^{2}$ de suelo en la ciudad: Kuri. La Jornada, 32.

» Lapavitsas, C. (2016). Beneficios sin producción. Cómo nos explotan las finanzas. Madrid: Traficantes de Sueños.

» Lefebvre, H. (2013). La producción del espacio, Madrid: Capitán Swing. (Publicación original: 1974).

» Levy, N. (2013). Dinero, estructuras financieras y financiarización: un debate teórico institucional. México: UNAM.

» OBRAS (2018). En busca de desarrollador. Obras, revista mensual sobre arquitectura, ingeniería y construcción en México, 45(542), 1-2.

» Ortiz, E. (2007). Housing policies in Mexico, impacts and perspectives. Trialog, Zeitschrift für das Bauen und Planen in der dritten Welt, 94(3/2007), 12-19.

»Palomero, J. (2019). Prólogo. En D. Madden y P. Marcuse, En defensa de la vivienda. Madrid: Capitán Swing.

» Ribeiro, L.C. y Diniz, N. (2017). Financeirização, mercantilização e reestruturação espaço-temporal: reflexões a partir do enfoque dos ciclos sistêmicos de acumulação e da teoria do duplo movimento. Cadernos Metrópole, 19(39), 351378.

"Rolnik, R. (2015). Guerra dos lugares. A colonização da terra e da moradia na era das finanças. San Pablo: Boi Tempo.

》 Rolnik, R. (2018). La guerra de los lugares. La colonización de la tierra y la vivienda en la era de las finanzas. Barcelona: Descontrol Editorial.

» Romero, G. (23 de julio de 2015). SEDUVI: como nunca hay boom de viviendas, pero el éxodo continúa. La Jornada, 30.

» Ruíz Tagle, J. (2020). Entrevista a Manuel Aalbers, Centro de Desarrollo Urbano Sustentable y Centro de Estudios de Conflicto y Cohesión Social, Santiago de Chile. Recuperado de: https://www.youtube.com/watch?v=0SwRDXDkDuk

"Salinas, L. (2019). El Estado y el mercado en la construcción de vivienda en la ZMCM. En L. Salinas y A. Pardo (Coords), Vivienda y migración, aportes desde la geografía crítica (pp. 109-128). Ciudad de México: Monosílabo - UNAM,

»Shimbo, L. y Rufino, B. (Orgs.) (2019). Financiarizacao e estudos urbanos na América Latina. Río de Janeiro: Letra Capital.

» SOMO - Center for Research on Multinational Corporations (2019). Financialization in the Global South. Programa recuperado de: https://www.somo.nl/_page/ topics-economic-justice/register-now-for-financialization-in-the-global-south/ programme/ 
Financiarización del desarrollo urbano en la Ciudad...

Víctor DELGADILLO

»Vázquez, R. (2018a). ¿De qué tamaño es el mercado de FIBRAS en México? Real Estate Market \& Lifestyle, La Guía Inmobiliaria de México. 120, 125-130.

»Vázquez, R. (2018b). Precios de vivienda acordes a demanda real. Real Estate Market \& Lifestyle. La Guía Inmobiliaria de México, 122, 94-98.

»Winter, E. (2019). México en un debate sobre financiarización, técnicas contables y de valoración inmobiliaria. En L. Shimbo y Rufıno, B. (Orgs.), Financiarização e estudos urbanos na América Latina (pp. 82-110). Río de Janeiro: Letra Capital.

\section{Víctor Delgadillo / victor_delgadill@hotmail.com}

Arquitecto (Universidad Autónoma de Puebla), Maestro en Planificación Urbana (Universidad Stuttgart, Alemania), Doctor en Urbanismo (Universidad Nacional Autónoma de México). Profesor investigador de la Universidad Autónoma de la Ciudad de México. Ha publicado 8 libros y más de cien artículos en libros y revistas especializadas sobre políticas urbanas, patrimonio urbano, centros históricos, derecho a la ciudad y gentrificación, entre otros. 